\title{
Transhumant Domicile and Educational Service Delivery for Pastoralist Afars Children in Ethiopia-Implications for Mobility Mapping
}

\author{
Ziyn Engdasew ${ }^{1}$, Yohanese Wogasso ${ }^{2}$ \\ ${ }^{1}$ Adama Science and Technology University, Adama, Ethiopia \\ ${ }^{2}$ Peking University, Beijing, China \\ Email: engdasewziyn1970@gmail.com, Yohanesey2@gmail.com
}

How to cite this paper: Engdasew, Z., \& Wogasso, Y. (2021). Transhumant Domicile and Educational Service Delivery for Pastoralist Afars Children in Ethiopia-Implications for Mobility Mapping. Creative Education, 12, 2356-2370.

https://doi.org/10.4236/ce.2021.1210178

Received: September 18, 2021

Accepted: October 19, 2021

Published: October 22, 2021

Copyright $\odot 2021$ by author(s) and Scientific Research Publishing Inc. This work is licensed under the Creative Commons Attribution International License (CC BY 4.0).

http://creativecommons.org/licenses/by/4.0/

\begin{abstract}
The aim of this study is to investigate the rationale for the seasonality of mobility, division of labor and organizations, and the availability of educational services in their routes and mobility corridors. It further looks for the convenience of the education service delivery to the mobile way of life and pastoralist livelihoods of Afar pastoralists and its implications for the need to have mobility mapping for effective delivery so as achieve educational equity. Hence, it follows a qualitative exploratory design so as to investigate the existing facts on the mobility of pastoralists' Afars. The qualitative data was gathered from purposively selected clan leaders. The data were categorized thematically and analysed qualitatively. The findings revealed that Afar pastoralists' mobility is rational, systematic, and well organized through their traditional social structure with a clear division of labor. Moreover, the education service delivery modalities are not fit in to the mobile way of life in which they are not following their mobility pattern, route, and corridors. This gives the insight to have a mobility mapping for clearer information of their mobility and school mapping so as to deliver proper education and achieve educational equity.
\end{abstract}

\section{Keywords}

Transhumance, Pastoralists, Nomadism, Mobility, Mobility Mapping, School Mapping

\section{Introduction}

Education has long been considered an indispensable weapon in fighting against 
poverty and a necessary first step in a long march towards socio-economic developments of society. Contemporarily, it is well-thought-out as an important instrument, which plays a key role in the social, economic, and political development of the marginalized communities. It helps the community to change their environment for their benefit and enables its members to make wise use of valuable resources in their environment. The recognition of education as an essential means for human and national development, therefore, pressed both the national and international community to consider it as a human right for disadvantaged groups like pastoralists.

Pastoralists are people who reside mostly in dry and remote areas of a country. The livelihoods of pastoralists mainly rely on their intimate knowledge of the surrounding ecosystem and on the well-being of their livestock. The types of livestock owned by pastoralists differ according to climate, environment, water and other natural resources, and geographical area (Rowley, 2010).

Pastoralism is a way of life, an economic activity and social system well suit to dry land conditions and characterize by a complex set of practices and knowledge that has conditioned the maintenance of a sustainable equilibrium among pastures, livestock and people. Today, there are around 200 million pastoralists in the world, but they are marginalized and generally not given due consideration in wider socio-political analysis and social service provisions. The incapability of pastoralists is to express their deep knowledge they have of their environment and how they carefully manage natural resources to generate wealth in sustainable manner cofounds the problem (Rowley, 2010).

Mobility is a key feature that symbolizes pastoralists' way of life. The word nomadic is used when mobility is high and in irregular patterns; transhumant when there are regular back-and-forth movements between relatively fixed locations; and sedentary for the rest (Rowley, 2010). Pastoralist lives in different zones where the potential for crop cultivation is limited, due to low and highly variable rainfall conditions, steep terrain, or extreme temperatures. They have long used their extensive and detailed knowledge of arid and semi-arid environments to increase livestock productivity (Krätli \& Schareika, 2010).

Pastoralists are positively taking gain of the ever varying attention of nutrition, particularly during the rainy season; by moving their animals than if they stay behind in one area. Hence livestock mobility is the most important strategy used by pastoralists to make best use of productivity under conditions of environmental unpredictability. Hence, mobility is rational utilization taking in to account the discontinuity of natural resources in space and time (Krätli \& Schareika, 2010).

Ethiopia is committed to the vision expressed in the Sustainable Development Goal Framework of "leaving no-one behind" in the provision of equitable development and education opportunity and lifelong learning. The country has a long-standing commitment to providing equal education opportunity to its entire people. Having such a back ground, this study attempted to look the rational 
for seasonal mobility and social structure of Afar transhumant pastoralists in Ethiopia and how the education service delivery fits to the pastoralists' way of life and their mobility routes.

Pastoralists constitute a large proportion of the Ethiopian population, at an estimated of 12 - 15 million people (14\% to $18 \%$ ), and they inhabit $60 \%-65 \%$ of the land area. Pastoralist communities have historically had limited access to social services such as education and health, and basic development infrastructures. Provision of education to pastoralist communities has been given special attention and the government gave a concern to offer special support to pastoralists, who had been deprived of educational opportunities in the past. The Federal ministry of Education introduced Pastoralist Education Strategy, developed in 2008, which pinpoint strategies to promote primary and secondary education and implemented for almost a decade.

Despite remarkable system expansion and gains in enrolment, and educational participation is still far below the national average in the pastoralist areas. A very large number of school-aged transhumant pastoralist children continue to be out of school and many who have enrolled do not complete due to the mobile way of life of the pastoralist community. These trends limits the country and challenged to fulfil the constitutional right of the citizen and consequently hinders the achievement of the Sustainable Development Goals (SDG) of which the country is signatory and of the long term national vision of becoming a Lower Middle Income Country (LMIC) by 2025.

In the last four consecutive years (2014/15-2018/19), the ministry annual education abstract shows that the enrolment rate of pastoralist Afar region, dominantly inhibited by transhumant pastoralists, was elusive. The recent MoE (2018/19) annual abstract revealed that primary education completion rate of the national average was $60 \%$, whereas Afar was $24 \%$. Even though offering primary education was promising, the national NER was $98 \%$ in $2018 / 19$ regional disparities exists, Afar was $55 \%$, especially majority of districts in the country hosting mobile pastoralist communities were lagging far behind the rest of the country.

The national pastoralist education strategy of Ethiopia (2017) takes into account the differing needs of mobile pastoralists (families whose livelihood is primarily dependent on livestock herding and involves seasonal mobility). Children enrolled from the mobile pastoralist background, where they enrol at all, are only a small minority (MoE, 2017).

It has depicted that livelihood-related factors (including, but not restricted to, mobility) cause interruptions to pastoralists' learning, continuity and progression in learning. Access, quality and relevance of education continue to be constrained for a range of reasons, with their mobility and school location being the biggest challenge. Moreover, the formal education delivery modality can meet the needs of agro-pastoralist children with a sedentary livelihood but has inherent limitations for mobile pastoralists (MoE, 2017).

The strategy document depicted that strategies and mode of deliveries in the 
past were not designed in accordance with the mobile life style of the majority of pastoralists in the country. Access to education continue to be constrained for a range of reasons, with mobility and absence of clear information of pastoralist movement pattern for school mapping and mobile schooling being the biggest challenge (MoE, 2016).

Hence, in this study an attempt is made to assess the mobility patterns of Afar pastoralists to shed light for future comprehensive mapping interventions. It tried to look also the rationale for mobility, availability of educational services in their mobility corridors, how the clan organization, structure and division labor practiced in their seasonal mobility, how we exploit it for educational service delivery and In order to achieve the above objective; the following basic research questions were set:

- What is the seasonality (regular/irregular) and pattern of mobility of Afar transhumant pastoralist community?

- What are the rationales for mobility forms of mobility organization (clan structure, division of labor) in their mobility?

- What is the efforts and support of local government to deliver social service in their mobility corridors?

The main objective of this study was to assess the rational for seasonal mobility, organization of mobility and availability of pastoralist sensitive educational service delivery modalities that can suit to the mobility pattern of transhumant pastoralists Afar in Ethiopia and its implications to mobility mapping for effective educational delivery.

The specific objectives of this study are:

- Examine the seasonal mobility (regular/irregular) of transhumance Afar pastoralist community.

- Investigate the mobility rationality; organizations of clans' structure, roles and its division of labour and its implication for educational delivery in their mobility.

- Scrutinize the efforts and support of local government to deliver education service in their mobility corridors?

\section{Research Design and Methodology}

This research undertaking was aimed at exploring the mobility pattern and mobility corridors of Afar pastoralist in Ethiopia. It has also investigated the rational for seasonality of mobility, social structures and organizations and the availability of schools, Alternative Education centers) in their routes and temporary settlements. It further looks for the convenience of the social service provision, mainly education to the mobile way of life and pastoralist livelihoods of the sample Afar clan members. Hence, it follows a research approach of a Qualitative exploratory design so as to investigate the existing facts on the rationale mobility and organizations of clans.

The principal researchers has been directly involved in the research under- 
takings and data collectors was employed from the Higher education institutions, regional Education offices. Desk reviews were conducted in consultation with all stakeholders and data collectors. The interview guides, checklists and guidelines for the study were also prepared and refined to use for data collections.

Interview guides and observation were the two major data collection. The researchers refined the instruments in consultation with experts in the field to reduce redundancy and overlap, and re-phrased some questions in order to enable eliciting the desired responses. Observation was used to assess the availability of social services in the mobility routes and corridors, like ABE centers, schools, water halls, veterinary stations, health centers. Members of the data collectors discussed in detail the instruments to heighten their common understanding of the issues for exploration and tools to be used. The key informants of the study were clan leader, school director, village chairpersons, elders, religious leaders, WEO heads, Development actors (Health extension workers).Observation was used to assess the availability of social services in the mobility routes and corridors, like ABE centers, schools, water halls, veterinary stations, and health centers.

Ethiopian pastoralists are found in four major sites (Afar, Borana, South Omo and Ethio-Somali) which need a national concern to look the mobility patterns. Even covering all ethnic groups of Afar region was seen as neither possible nor desirable, and sample clans were selected. A tentative list of Mobile Afar clans was prepared in consultation with the regional pastoralist affair offices level, to develop purposive sample of clans. Upon the arrival of the researcher team in Afar, further discussion was held with the regional education officials and final selection of the clan to be included in the study was made. In as much as possible, the selection of clans was purposive based on the areas where the population is mobile pastoralists and mostly mobile in different seasons.

Key informants were also selected using purposeful sampling techniques considering their knowledge, responsibility and experience in the area of pastoralist livelihood and service delivery like, education. The data collectors needed to use local language translators, these were selected and recruited from local people who are fluent in speaking the language and have awareness on the culture and education situation of the area. Observation was made and Interview was conducted in local language and transcribed and translated in to English language.

The researchers categorized the interview results in different thematic areas and analyzed the qualitative data based on respondents view and thematic analysis and narrate qualitatively. Observation reports were written so as to supplement and complement the interview results.

\section{Results and Discussion}

\subsection{Mobility-Livelihoods of Pastoralist}

Pastoralist mobility is often regarded as an important characteristic of pastoralist societies and their ways of production in Africa. However, the rationale and importance of pastoralist mobility changes along with the various discourses, and 
just as important-the interpretation varies with the professional background of the researcher. The positive perception of mobility is relatively new among researchers of dry lands, and this is not a new line of thought among social scientists studying pastoralists (Dyson-Hudson \& Dyson-Hudson, 1980). Especially anthropologists (e.g. Dyson-Hudson, 1972; Evans-Pritchard, 1940) and others studying pastoralist societies (Johnson, 1969) have pointed to the flexible strategies employed by pastoralists.

Pastoralists are characterized by the almost exclusive use of family labor for production and direct dependency on livestock rearing for subsistence requirements. High dependency on pasture and less dependency on the modern production systems also distinguish it from the other ones. However, they have considerable capacity for change and improvement (Swift \& Hamilton, 2001).

Organization of on-farm and off-farm activities, which together provide a variety of procurement strategies for food and cash, maintains livelihood systems. Households' total resource is based not only on their productive activities and endowments but also on legal, political, and social position within society (Swift \& Hamilton, 2001). Livelihood systems incorporate the present situations and the short-term and long-term perspectives. The objective is not only to preserve current patterns of consumption but also to avoid destitution or sacrificing future standards of living. The risk of livelihood failure determines the vulnerability of a household to income, food, health, and nutrition insecurity, which has direct implications for education delivery (Ellis, 2000).

Pastoralists live in some of the harshest environments in the world. Conflict and migration and other socio-cultural and environmental challenges are part of their daily life. Moreover, these pastoralists mostly lack vital infrastructures such as adequate roads, schools, markets, and health facilities. Due to their physical and social isolation, there are limited government social services, like education, available in such pastoral areas. In addition, pastoralists remain isolated and marginalized because of poor economic integration with their national economies, and their difficult circumstances are exacerbated by conflict within and outside the communities (Kandagor, 2005).

Mobility from place to place in search of pasture and water for their livestock is a lifelong routine for pastoralists. Bearing these constraints in mind, there is needed to institute understanding for pastoralists and their movement patterns. It is important not to stop them from this practice but instead to institute vital development interventions, such as education service provision, would have to recognize and adapt to this aspect of pastoralist life (Mandivamba, 1999).

\subsection{Education Policy and Pastoralists in Ethiopia}

Ethiopia has committed herself to universalize primary education without any discrimination. The FDRE constitution, Article-1; sub-article-2 states that the fundamental rights and freedoms specified shall be interpreted in a manner conforming to the principles of Universal Declaration of Human Rights and interna- 
tional covenants on human rights and international laws adapted by Ethiopia.

Moreover, Article 41, sub article 4 of the covenant states that, it is the obligation of government to increase the allocation of resources to public health, education and other social services. This principle clearly indicates that there are legal basis and policy support for universalizing of primary education in Ethiopia.

The education and training policy of the Ethiopian government further stated that a special assistance will be given to those who have been deprived of educational opportunities and steps will be taken to raise the educational participation of deprived regions (TGE, 1994).

The Government is placing particular emphasis on pastoralist education with the firm belief that the long-term development of the country rests upon the expansion and provision of quality education. The Government's desire to improve the provision of quality education resulted in the formulation of the education and Training Policy (ETP), which encompasses the entire education and training sector. In 1997 the Government of Ethiopia launched the first five year Education Sector Development program (ESDP-I) within the framework of ETP as a part of a twenty-year education sector indicative plan. The main thrust of ESDP is to improve quality, relevance, equity, efficiency and to expand access with special emphasis on primary education in rural and urban areas, as well as the promotion of education for girls in as attempt to achieve universal primary education by 2015 (MoE, 2004).

This was an outcome of the Government's deliberate plan to implement rural development policies and strategies and to ensure sustainable development for the rural population which constitutes $85 \%$ of the country's total population. Creating access to primary education for all school-age children and thereby producing educated farmers and other workers who utilize new agricultural technologies and produce for market is indispensable for the realization of the rural transformation strategy (MoE, 2004).

It is believe that the lives of pastoralist and semi-agriculturalists will only be improved through better and effective education and skill training and livelihood diversification. Hence, in order to meet the basic education needs, the government has adopted alternative approaches and strategies (MoE, 2004).

Available studies and documents indicate that education for Ethiopia's pastoralists' lags far behind education for the general population, and that child enrolled from the mobile pastoralist background, where they enrol at all, are only a small minority. All the indicators of school participation and achievement (i.e. access, enrolment, retention, completion) in the pastoralist areas are below, and usually far below, the national average. Availability of well-established data on mobility pattern of pastoralists is pitfall in the implementation of strategies and proper delivery of education. At present, the necessary full detail about mobility patterns of pastoralists and patterns of resource use are not available to guide educational planning in Ethiopia (MoE, 2016).

The Afar Regional State is inhabited by 1.7 million people among whom $97 \%$ 
are pastoralists' who live in desert areas of the region (CSA, 2008). The pastoralist Afar region mainly consists of lowlands, with a predominately hot and dry semi-desert climate. The economy is predominantly based on a pastoralist economy. The main economic activities are subsistence-based animal husbandry, mixed-livestock management including but not limited to camels, cattle goats, and sheep, which often rely on seasonal and periodic mobility. Consequently, many Afar people migrate seasonally in search of grazing places and water sources for their herds (MoE, 2016).

\subsection{Clan Structure and Mobility Organizations}

Basically, the Afars are classified into two distinct descent groups: the Asaimara (red) and Adaimara (white). The former is considered a nobility group, while the latter is said to form the class of the commoners. In terms of the clan, it is divided into twelve indigenous groups, which are found in Ethiopia, Eritrea, and Djoubiti (Markakis, 2004).

Pastoralist Afars have a social organization that is similar to that of many other pastoral societies in East Africa such as the Somali. Central to the Afar social structure is descent and affinities. The Afar have a patrilineal descent system based on which a person belongs to a particular clan (mela). Their mobility patterns and every other decision are mostly organized and led by clan structure.

Afar settlements are composed of a mixture of clans although each locality is recognized with a major clan. This makes it easier to organize social, economic, and political support in times of crisis and seasonal mobility. Afar clan members' are expected to share not only their resources but also behaviours and help each other in emergencies and defend themselves whenever they faced any attack and crisis in their mobility from one place to another.

Related to intra-clan sharing behaviour, one of the Afar elders says: "Sagage' $r i$ nama lakal masa" (Literally: a cow's tail is equidistant from both its legs). This means those belonging to the same clan share and shares equally, both the good and bad. They have a custom of maintaining solidarity through a strong clan identity. Clans are represented by the clan leader, who access leadership status based on their age, strength in decision-making and overall credibility in the society. Clan leaders are entrusted with the responsibility of regulating the behaviours of clan members in their mobility.

The question was posted on how we can exploit this leadership strength and representation towards the provision and management of education service that can fit the Afar mobile pastoralist livelihoods. The interviewees' clan leader affirmed that:

"it is the tragic and missed opportunities in the decade's efforts of the government to access educational services for Afar pastoralists. We are still looking for education delivery modality that can fit our mobile way of life and managed by our own leadership".

Afar clan leaders claim that their strong social structures, division of labor, 
and age-old traditional institutions which fit and serve in their mobile way of life are ignored to be considered to provide government development interventions including educational service deliveries.

\subsection{The Rationale for Mobility}

Informants unanimously confirmed that in Afar arid and semi-arid areas, mobility is the foundation of livelihoods of the Afar community. Historically, the economy of the Afar was based on multi-species livestock husbandry. But with increased vulnerability to drought and ecological disasters, they now depend mainly on camel and goats.

Frequent drought in the last years highly affected not only herds but also camels. One of the interviewee clan leaders says: "These days Afar pastoralists prefer to breed only goats that can survive severe droughts".

Afar pastoralist used their indigenous knowledge of arid and semi-arid environments to maximize livestock productivity and safeguard from the draught. In this case, mobility is an effective and successful strategy to protect their livestock and themselves from unpredictable, vulnerable, and dynamic environments. Hence, mobility is the right means to maintain an ecological balance between themselves and the natural environment.

Moreover, Afar pastoralists are positively exploiting the ever-changing concentration of nutrition, particularly during the rainy season; by moving their animals than if they remained in one area. Livestock mobility is the principal strategy used by Afar pastoralists to maximize productivity under conditions of environmental variability. Hence, the mobility of Afar pastoralists is rational exploitation taking into account the discontinuity of natural resources in space and time.

\subsection{Division of Labor in Mobile Way of Life}

As per the interviewee, in the Afar household, men are heads of respective families and generally accepted as an authority figure and have the lion share of rights over properties in the pastoralist economic activities. Household heads also decide on such matters as mobility, mobility corridors, and mobility patterns. Although household decision-making is often based on subsequent negotiations with women, men have the ultimate decision-making in the division of labor and mobility corridors selection.

The household division of labor is based mainly on gender and age. Accordingly, male adults manage the herd of the household. The husbands carry out the herding, milking, and selling of animals. The woman has also a responsibility to fetch water, grind grains, and prepares food in the house. She also sells small stock animals in nearby towns. Women are also actively involved in the preparation of temporary shelters (Senan Ari) where ever they settle in their mobile way of life. Children assume a prominent role in mobile herding and related activities. Children are also responsible to keep calves and small stocks. 
Livestock is an individual property even though it is considered as the property of the whole family. In the households, children have their own livestock. Following birth, a child will reward female goats or a camel "to see the luck". At the clan level, the clan leader has the ultimate say on the clan members' mobility and security matters. The clan leader plays a role to mediate clan members with the government. He is highly responsible for the security and well beings of the clan members.

Being aged is an important factor in the traditional leadership structure of the Afar. Elders have the authority to command resources and shape the behavior of children and grandchildren. Elders have a figurative authority over new generations and hence play a determinant role in the delivery of informal education and disciplining of the young generations. Through fairy tales, proverbs and stories, elders pass on the tradition, folk culture, and wisdom to successive generations.

The mobility season and pattern are decided by the clan leaders and establish $B O D D A$ and prior information on their movement pattern, destination, duration of stay and availability of water and pasture, and security in their settlement were well gathered by Eddo.

According to Afar clan leaders, Eddo comprised of three, five, or seven members (Mostly Odd number for the purpose of voting) assigned by the clan leader in consultation with the elders due to his physical strength to walk long distances, the loyalty of his behavior and trusted by the community. These groups are responsible to the clan leader and elders through FEAMTABA. The clan leaders chair the community and dispatch information/DAGU/for final decision and mapping the mobility routes and corridors.

FEAMTABA calls the clan members and communicates to the family members through ERRENA, and DANTE and shares what they have observed and organizes their integrated plan to move the places where pasture and water are available. Afar elders say ARENA will take the responsibility to establish rules and regulations implemented in the mobility corridors and punish accordingly whenever someone or some group violates the already set manners of mobility. Children herders will be assigned and separate militant groups have organized who defend any attack. They say "It is better to lose the life of the person than losing cattle". FEMEA ABOTE will select from the youngsters who control and ordered the young militants.

EDDO maps the mobility routes and indicates the topography of the route and their settlement areas, indicating plain, mountains, terrains, and slopes using different symbols and icons. Mobility routes and corridors which are insecure and hazardous are well symbolized and indicated, well informed ahead for those who move in that route to be precautious and take the necessary care. It has also the responsibility to propose the duration of time where the clan members will stay in the newly discovered sites of settlement depending on the availability and amount of water and pasture in the areas.

Division of labour for defending any attack from opponents, taking care of 
those clan members in their journey, role of Quran teachers and religious leaders has been discussed and identified. The religious leaders pray to ALLAH to have a safely journey of the clan members which is free from enemies attack and snake bites and other hazards. The Quran teacher makes him ready to give Quran education where even children settle in mass during night time.

Even though mobility, its patterns and division of labour are an agenda for discussion, respondents anonymously spelt out that modern schooling, continuity of their children learning and dropout of children are not an issue for discussion in their seasonal mobility. Most of the pastoralist Afar parents demand that education and schooling should be there in their settlement camps. The issue of children learning is an issue whenever they settle somewhere.

In this regard, Afar Elders said once "We will learn and our children will learn if you bring us a school which has feet, a school which can walk with us, it is not only for our children but also we need also adult education for us".

Questions was posed how much the clan structure and sub structures are capable enough to own and run the secular education provision with dedication and passion just like Quran education and mobility plans and division of labour. They confidently affirmed that clan structure and sub clan strata are strong enough to manage the secular education provision with the support of local government. They revealed that if such structure belongs to and take the responsibility for the management and provision of education for their own clan members; it will create a sense of ownership and strives to educate more number of their clan members. This time there is a hidden competitions between clans how many of the clan members complete grade 12, graduate from universities and join in the government bureaucracy. Such a sense of competition between clans will motivate to run and support the provision of secular education at the clan level.

\subsection{Mobility Pattern and Seasonality}

There are diverse kinds of mobility and the degree of mobility may change according to environmental conditions in the region. As per the respondents, Afar pastoralist mobility can be seasonal, regular as a pendulum between two or more well-defined pasture areas, following marked transhumant routes that have not changed for decades, towards newly available resources.

On their mobility pattern, pastoralist Afars may label all types of movement which include substantial irregularities as nomadic, regular back and forward between highlands and low lands. Their movement is not necessarily only for ecological reasons: it can be for trade, because of conflict, or to escape from Testesflies for their cattle and mosquito for their clan members.

Afar pastoralists' clans divide their season in to four major classifications. Hence, their mobility has also planned according to these seasonal conditions and opportunities to be exploited. These seasons are well known by Afar pastoralists. 
- GILALE (Dry and windy months) September 15-February 15 occasionally light rain may appear which is called $D A D A O$ ), especially three days rain may existed from September 15-October 20, called KAIRERO, if it rains well, grasses will grow or if the rain is too little, it will damage the existing grasses.

- SEGUM (Occasional Rainy-Belg rain) February 15-April 15.

- $H A G A Y$ (Dry) April 15-July 15.

- KARMA (Rainy) July 15-September 15.

Afar pastoralists move from place to place seasonally in search of better nourished pastures and plants. Children of pastoralists like to move together with their livestock to get better nourished milks from their cows and goats. But, most of the time they feel that the milk that can get from lactating animal remains from mobility are nutritionally poor than the milk that they will get in the new mobility corridors. The cow remains in the resident areas will not get diverse kinds of plants and pasture to eat hence the nutrition in the milk is not well nourished.

Consequently, children prefer to dropout of schooling and move with the lactating animals, who is going to search new settlement areas. This notion is also shared by most parents that if the children could not get nutritional milk at their early age, he will be weak physically and mentally and will become unfit to the pastoralist life in the future.

In practice, interviewees confirmed that most of children do not want to stay and remain in their home when their elder brothers and family members leave the area with their cattle. They highly eager and need to move with cows and camels in which they know milk is available there and children are free to play different types of games like ABUDA. Hence, their children obliged to drop schooling and go with their family members.

The Quran teacher will move with them due the incentive promised from their parents that when a child finished the Quran education that he will be rewarded of four goats from a child family. Question was posed to interviews how we can exploit such school settings to introduce secular education after Quran education. They anonymously agree that their children demands literacy and numeracy education equivalent to Quran education. One of the clan leaders say that "Quran education is for heaven sake it is also crucial for earthily life, so we need to have both for our children."

\subsection{Local Governments Support and Educational Service Delivery}

The mobility decision and strategy is not so much transparent for local governance. Clan leaders are interested to consult the local government bodies in their mobility and their role in mobility decision is insignificant. It is only in some occasion of severe draught that clan leaders communicate with local governance to inform the disaster and inform if security problems are expected from neighbouring ethnic groups, like Issa Somali.

Mobile ways of life is not claimed to be a factor for low educational participa- 
tion of Transhumant Afar children as many of the respondents' agreed. Woreda education bureau official stated:

"Mobility itself is not the problem. We are not using their mobility systematically. An alternative was proposed that an additional learning centre be built at both sites of migration. Many organizations have discussed setting up more than one educational site, so that if communities follow regular migration paths between 2 - 4 consistent locations and seasonality, education can easily accessed at the place where it was left off".

The implication of the saying of the respondent is that, mobility is their right ways of life, but education service delivery isn't available in their mobility routes. The mobility pattern and mobility corridors are not clearly scrutinized and documented as an input for school mappings. Hence, schools are erected in different parts of the desert areas, but could not be accessible for transhumant pastoralist children, so it is common to find schools without students especially in the months of February, March and April.

\section{Conclusion and Ways Forward}

Pastoralism is a way of life for many people who live in Afar region. Even if Afar pastoralists are mobile in their livelihood, little is known about the mobility rationale and patterns of their movements. In arid and semi-arid pastoralist's areas, mobility is the foundation of livelihoods of Afar community. Mobility in the Afar pastoralist context is sound and rational. It is not haphazard rather systematic, planned and well organized through their traditional structure. The case in Afar clan indicated that Elders, clan leaders, household headers, and clan structures established will clear role in order to decide their mobility patterns and seasons, where they will settle, for how many months, when do they move back to their original places. The clan groups divided into sub-clans and settle in different areas. They will establish rules and regulations and develop structures with a clear division of labor in each segment of the clan group members and sub-clan groups, which is not optimally exploited in the educational delivery.

They decided to move in search for better and variety of pasture so as to secure the nutritional demand of their cattle consequently to get well nutritional milk and meat for their family members. This seems one of the cases why children of pastoralists are attracted to move with their family members and do not access and sometimes dropout of formal schooling.

The study revealed that great deal of the pastoralist Afar mobility can be characterized by seasonal circular movement between the inheritance camp and watering and pasture lands. Occasionally, they prefer to be transhumance in order to exploit optimally to the variable resources during the draught seasons. Elder with clan leaders will map the mobility routes and indicate the topography of the route and their settlement areas, indicating plain, mountains, terrains, slopes and plains using different symbols and icons. Mobility routes and corri- 
dors which are insecure and hazardous are well symbolized and indicated, well informed ahead for those who move in that route to be precautious and take the necessary cares.

The findings depicted that clan structure and sub clan strata are strong enough to manage the secular education provision with the support of local government. It clearly revealed that if such structure belongs to and shares the responsibility for the management and provision of education for their own clan members; it will create a sense of ownership and strives to educate their clan member. Hence, the educational delivery modality designed and implemented should have to fit to their mobility and pastoralist's way of life. It requires to better suit to them by measures that facilitate attendance in schools and learning/education centers on migratory routes, it enables to ensure that the school/center network is able to maintain continuity of learning for mobile pastoralist children.

Elders said once "We will learn and our children will learn if you bring us a school which has feet, a school which can walk with us". This implies that pastoralist communities are the demand for education, but education can suit to their mobile way of life. The existing schools, ABE (Alternative Basic Education) centers, health service infrastructures and water points are not established in accordance with their mobility corridors and settlements.

This has further implication for the need to intensively investigate and sketch the mobility pattern and match the social services and education provisions in accordance with their mobility corridors and, settlements. Schools, ABE centers health facilities and water points should be designed based on the mobility mappings of the pastoralist's community. It will become imperative to understand the features of Afar pastoralists and their clans (Vibrant, Transhumant and settled pastoralists) and adapt its diversity for the implementation of different educational delivery modalities.

\section{Conflicts of Interest}

The authors declare no conflicts of interest regarding the publication of this paper.

\section{References}

CSA (Central Statistical Agency) (2008). Population and Housing Census of Ethiopia. Central Statistical Agency.

Dyson-Hudson, R. (1972). Pastoralism: Self-Image and Behavioural Reality. Journal of Asian and African Studies, 7, 30-47. https://doi.org/10.1177/002190967200700103

Dyson-Hudson, R., \& Dyson-Hudson. (1980). Nomadic Pastoralism. Annual Review of Anthropology, 9, 15-61. https://doi.org/10.1146/annurev.an.09.100180.000311

Ellis, F. (2000). The Determinant of Rural livelihood Diversification in Developing Countries. Journal of Agricultural Economics, 51, 289-302. https://doi.org/10.1111/j.1477-9552.2000.tb01229.x

Evans-Pritchard, E. E. (1940). The Nuer. The University Press, Oxford.

Johnson, D. L. (1969). The Nature of Nomadism-A Comparative Study of Pastoral Mi- 
gration in Southwestern Asia and Northern Africa. Research Paper No 118, Department of Geography, University of Chicago.

Kandagor, D. R. (2005). Rethinking Pastoralism and African Development: A Case Study of the Horn of Africa. Egerton University.

Krätli, S., \& Schareika, N. (2010). Living Off Uncertainty: The Intelligent Animal Production of Dry land Pastoralists. European Journal of Development Research, 22, 605-622. https://doi.org/10.1057/ejdr.2010.41

Mandivamba, R. (1999). Land Tenure and Sustainable Development in Africa: Experiences from Community Based Natural Resource Management, Models for 21st Century Africa. African Studies Centre.

Markakis, J. (2004). Pastoralism on the Margin. Minority Rights Group International.

MoE (Ministry of Education Ethiopia) (2004). Educational Annual Abstract.

MoE (Ministry of Education Ethiopia) (2016). The Situation of Pastoralist Education in Ethiopia.

MoE (Ministry of Education Ethiopia) (2017). National Pastoralist Education Strategy. Ministry of Education Ethiopia.

MoE (Ministry of Education Ethiopia) (2018/19). Education Annual Abstract.

Rowley, T. (2010). Participatory Digital Map Making in Arid Areas of Kenya and Tanzania. Dry Land Change Group.

Swift, J., \& Hamilton, K. (2001). Household and Livelihood Security. In S. Devereux, \& S. Maxwell (Eds.), Food Security in Sub-Saharan Africa. ITDG Publishing.

TGE (1994). The Education and Training Policy. 